\title{
Intuições "Lingüísticas" sobre a Língua de Sinais, nos Séculos XVIII E XIX, A PARTIR da Compreensão de Dois Escritores SURDOS DA ÉPOCA*
}

("Linguistic"Intuitions about Sign Language in the 18th and 19th Centuries, According to the Understanding of two Deaf Writers from that Time)

Regina Maria de SOUZA (Faculdade de Educação/Unicamp)

O problema não é apresentar a obra literária em conexão com o seu tempo, mas sim tornar evidente, no tempo que a viu nascer, o tempo que a conhece e julga, o nosso.

Walter Benjamim

ABSTRACT: This paper discusses some "linguistic" conceptions about Sign Language which were current in the Modern Age, based mostly on two texts: one a book written by a deaf typographer and published in Paris in 1779; the other an essay written in 1840 by a deaf professor. Similarities will be shown to hold between their statements and several extant concepts and prejudices about what is generically called "Sign Language" from a linguistic point of view. Based on those same texts, considerations which are pertinent to the present will be made regarding the role of Sign Language in Deaf Education.

KEY-Words: Sign Language; Deaf Education; Philosophy of Language; Education $^{1}$

\footnotetext{
* Este trabalho foi elaborado, originalmente, a pedido das professoras dras. Maria Cristina Figueiredo Silva, coordenadora do GT Teoria da Gramática, e Ronice Muller de Quadros, membro do GT Linguagem e Surdez, para o XVII Encontro Nacional da ANPOLL. O lugar de sua apresentação foi o da Mesa: Investigações sobre a língua de sinais brasileira, organizada pelos dois GTs. Segundo as solicitantes, o objetivo da presença de uma pesquisadora estranha ao campo da sintaxe era o de trazer a diferença do olhar - o da autora deste estudo - conformado pela filosofia da linguagem e apurado pelo que, desse campo, pode fazer derivar para sua área específica de atuação: a Educação.

1 Agradeço ao professor e amigo Dr Leland McCleary pela tradução do abstract.
}

D.E.L.T.A., 19: 2, 2003 (329-344) 
RESUmo: Este estudo apresenta e discute algumas concepções "lingüísticas" sobre a língua de sinais circulantes no periodo que denominamos modernidade a partir, principalmente, de dois textos: de um livro, escrito por um tipógrafo surdo, publicado em Paris em 1779, e de um ensaio assinado por um professor, também surdo, escrito em 1840.

O objetivo da presente reflexão é mostrar a similaridade de algumas colocações, realizadas por eles, com certos conceitos e preconceitos ainda existentes sobre o que seja, do ponto de vista lingüístico, o que genericamente se denomina "língua de sinais". Considerações sobre seu papel na educação de pessoas surdas também serão realizadas, e projetadas para o presente, a partir daqueles mesmos textos.

Palavan-Chaves: Língua de Sinais; Educação de Surdos; Filosofia da Linguagem; Educação

Como é bem conhecido, um filósofo, em geral, com muita naturalidade, reconhece o seu não saber. Enclausura-se em certezas, anuncia o extermínio do próprio objeto. Da mesma forma, é facilmente cativado pela história das idéias - pelo desvelamento de seus traços arqueológicos e/ou genealógicos. Deixando-me levar por esse fascínio pelo passado, decidi retornar aos séculos XVIII e XIX a fim de revisitar as intuições que dois surdos franceses, Desloges e Berthier, possuíam sobre a língua de sinais, sua gramática e importância na educação de surdos. Esclareço, a seguir, um pouco melhor, os motivos dessa escolha.

Desloges e Berthier pertenceram a um período - a modernidade - no qual foi articulado, e/ou cristalizado, um conjunto de heranças a que muitos de nós procuramos romper (por exemplo: a fabricação do homem como positividade, o estabelecimento de padrões normativos e universais sobre o desenvolvimento humano e, em conseqüência, o engendramento de uma pedagogia conformadora etc. $)^{2}$ Refiro-me à ilusão de que a pós-modernidade nos traga, enfim, algo de novo, nos projete, a nossos corpos e instituições em outras e novas ordens, sem nos darmos conta de que, provavelmente, o lugar de onde falamos ainda é o da imobilidade e fixidez. Estamos, segundo me parece, não rompidos, mas ainda orbitando, de certa forma, em torno de uma certa ordem alojada em nosso passado. Daí porque retorno a ele.

\footnotetext{
Uma discussão mais apurada sobre o legado da modernidade pode-se ler em: FOUCAULT, 1991 e 1998; NARODOWSKI, 2001, entre outros.
} 


\section{Os textos e os autores inspiradores deste estudo}

Deixar-me-ei conduzir, mais de perto, por dois textos originalmente escritos em francês e publicados em Paris: A Deaf Person's Observations About An Elementary Course Of Education For The Deaf ( por Pierre Desloges, publicado em 1779) e The Deaf Before And Since The Abbé de L'Epée (por Ferdinand Berthier em 1840) ${ }^{3}$.

Pierre Desloges nasceu em 1747, em Le Grand-Pressigny, e ficou surdo com 07 anos, provavelmente, devido ao sarampo. Com 21, mudou-se para Paris, vivendo em situação de grande dificuldade financeira. Com 27 anos aprendeu a língua de sinais francesa com os surdos que conheceu nessa cidade. A partir daí, segundo ele, passou a se valer da escrita para se opor à tese de que a educação de surdos deveria basear-se no ensino da fala, como defendia na época o cônego Deschamps, a quem toma como principal interlocutor em seu livro.

Ferdinand Berthier, surdo congênito, nasceu em 1803 na cidade de Louhans, na França. Iniciou seus estudos no Instituto de Jovens Surdos de Paris (como atualmente é conhecida a escola que Epée fundou) ${ }^{4}$ aos oito anos. Foi aí professor e criou a primeira organização para/de surdos do mundo.

\section{As teses de Pierre Desloges e a concepção iluminista sobre a linguagem}

Segundo Lane e Philip (1984), Desloges foi a primeira pessoa surda a publicar um livro com o objetivo de defender a tese de que "a língua de sinais dos surdos era o veículo próprio para a sua instrução" (p.28).

Desloges explica, logo no início de seu prefácio, o motivo que o levou a escrever:

"Eu sou invariavelmente questionado sobre o surdo. Mas muito freqüentemente as questões são tão risíveis como absurdas; elas meramente provam que quase todas as pessoas têm as mais falsas idéias possíveis sobre nós; poucas pessoas têm uma noção de nossa condição, de nossas capacidades, ou de nosso modo de comunicação uns com os outros em língua de sinais.

(...)

\footnotetext{
${ }^{3}$ Esses dois trabalhos foram traduzidos para o inglês e publicados em: LANE, Harlan \& PHILIP, Franklin, 1984. Os originais, infelizmente, não me estão acessíveis até o momento.

${ }^{4}$ Charles-Michel de L’Epée, abade francês (1712-1789), foi o primeiro educador a reunir pessoas surdas em um mesmo local com o objetivo de ensiná-las através da linguagem de sinais. No início, mantinha sua escola com recursos próprios. Com o tempo passou a receber contribuições, entre elas, do próprio rei Luis XVI. Em 1789, em seu leito de morte, soube que a Assembléia Nacional acolhera seus alunos surdos e que transformara sua escola em instituição nacional, condição que se mantém até nossos dias.
} 
Como qualquer francês que veja sua língua depreciada por um alemão, que conhece no máximo poucas palavras do francês, me sinto extremamente obrigado a defender minha própria língua dos falsos ataques dirigidos contra ela por Deschamps (...)" (Desloges, 1984: 30)

Três páginas adiante, Desloges faz uma citação de Deschamps obrigando, de certa forma, seu próprio adversário a admitir que a educação oral dos surdos "não é acompanhada de prazer, longe disto, elas (nossas lições) parecem ter a participação de uma grande dose de aborrecimento e de desgosto; elas são doentias..." (Deschamps, cit. Desloges, 1984: 33, grifo meu)

Sobre os efeitos de tais constrangimentos sobre o aluno, o cônego dá o seguinte conselho ao educador: "somente podem ser superados com considerável vexame, determinação e paciência. Nós devemos trabalhar com tudo isto de modo enérgico, caso contrário é impossível dar a eles (aos surdos) o uso da fala". (p. 33, grifo meu)

Assim sendo, me parece que a primeira tese que Desloges deseja defender é a de que a educação, centrada no ensino da fala, provoca humilhação e constrangimento no aluno.

Em 1998, Perlin, pesquisadora surda, transcreve, em sua dissertação de mestrado, uma série de narrativas que mostram a presença dessa mesma situação ainda em nossos dias. Dentre elas, recorto a seguinte:

"Usava aparelho e odiava-o, mas estava sendo imposto, inclusive com nota no boletim. Havia ameaças. Se não usasse o aparelho era sinal de que estava indo mal nos estudos, não estava querendo ser perfeita, estava fugindo das regras escolares. Acreditava no que me diziam de que quando crescesse seria igual aos ouvintes. Um dia descobri que nunca iria falar como eles, seria mesmo impossível. Era preciso pegar o meu jeito próprio de ser surda. (...) No meu grupo de escola de II Grau havia tanta fala e eu sofria por não conseguir acompanhar. (Perlin, 1998: 74, fragmento da narrativa de P., uma surda de 26 anos, sobre sua vida).

A partir da idéia da inadequacidade da fala para o ensino de surdos, Desloges passa a defender que a educação, dos que não ouvem e falam, deve ser inscrita na língua de sinais. Atribui ao abade de L'Epée a genialidade de ter descoberto que seu uso, na/pela escola, poderia oferecer o principal meio de acesso à escrita e à leitura (do francês) pelo surdo. ${ }^{5}$

\footnotetext{
5 L'Epée, em um primeiro momento, aprendeu a língua de sinais com surdos que viviam em Paris. Todavia, julgou que, para a instrução escolar e ensino da escrita, a língua de sinais deveria sofrer modificações a fim de que pudesse espelhar a gramática francesa. Criou, assim, o que chamou de Sinais Metódicos: sistema gestual artificial que mesclava elementos da língua de sinais (francesa) com outros inventados por ele para marcar características lingüísticas da língua francesa como flexões, conectivos, sufixos etc. Desloges
} 
"De fato, uma vez que Epée concebeu o nobre projeto de se devotar à educação do surdo, ele sabiamente observou que eles possuíam uma linguagem natural para se comunicarem entre si. Como essa linguagem não era outra senão a línguagem dos sinais, ele percebeu que se ele conseguisse aprendêla, o triunfo de sua empreitada estaria garantido."(Desloges, 1984: 34)

Mas adverte:

"o abade Epée não foi o inventor ou criador dessa linguagem; muito pelo contrário, ele a aprendeu do surdo." (p. 34)

Segundo ele, L'Epée, no exercício de sua missão como educador de surdos, considerou a si mesmo como

"um homem repentinamente transportado a um povo estrangeiro ao qual ele queria ensinar sua própria língua nativa [o francês]; ele julgou que o melhor meio para conseguir isto seria aprender a língua do país [estrangeiro] a fim de que facilmente pudesse dar àquele povo [surdo] instruções compreensíveis" (Desloges, 1984: 34).

Desloges, do mesmo modo, entendia que uma pessoa apenas poderia compreender uma segunda língua - como para ele era o francês para os surdos - se a gramática da língua estrangeira pudesse lhe ser explicada em sua língua materna. Dessa forma, segundo ele, a pessoa

"aprenderia a nova, desconhecida língua facilmente com a ajuda de sua língua nativa." (Desloges, 1984:34)

Essa posição de Desloges se coaduna inteiramente com uma das idéias vigentes sobre a aquisição da sintaxe de uma língua estrangeira, segundo a qual o aprendiz só é bem sucedido se puder acessar as hipóteses sintáticas já construídas por ele durante a aquisição de sua primeira língua.

Uma segunda tese que defende é, pois, que a aquisição da língua escrita do país onde reside o surdo é mais facilmente adquirida se sua gramática puder lhe ser ensinada em sua língua primeira (sinais).

Em nossos dias, vários educadores e lingüistas consideram que, idealmente, uma criança surda deveria adquirir primeiramente a língua de sinais e depois a língua majoritária. Como falar requer um programa sistemático de habilitação oral, portanto, demanda procedimentos a serem realizados em clínicas de fonoaudiologia e de audiologia, quando se discute 
a $\boldsymbol{e d u c a c ̧ a ̃ o ~ d e ~ s u r d o s ~ u m ~ n u ́ m e r o ~ e x p r e s s i v o ~ d e ~ a u t o r e s ~ c o n s i d e r a ~ a ~ e s c r i t a ~}$ como a modalidade da língua majoritária a ser ensinada pela escola. Assim sendo, defendem a tese de que a educação da pessoa surda deva ser bilingüe: o currículo geral ensinado em língua de sinais e a língua majoritária escrita como segunda língua. Entretanto, as iniciativas nessa direção são recentes (não possuem mais que 30 anos) e, em muitos países, como no Brasil, se ressentem com o modelo de inclusão escolar usualmente praticado, pois na melhor das hipóteses, nele a língua de sinais possui valor instrumental equiparável ao braille (no sentido de ser um recurso a mais de acesso à língua majoritária) e, portanto, não considerada como uma língua de fato. Para uma discussão mais adensada, sugiro a leitura de Souza e Cardoso (2001); Skliar (1999); Kyle (1994); Padden e Humphries (1988).

Uma outra réplica que Desloges faz a Deschamps se refere ao fato de o cônego afirmar que os sinais apenas serviriam à expressão de coisas físicas e necessidades corporais, sendo, portanto, uma linguagem que apenas poderia atender a objetivos imediatos ou demasiadamente concretos. Desloges, ao rebater essa afirmação, não pôde escapar do horizonte discursivo de sua época sobre a linguagem - aspecto esse que, julgo, convém ser lembrado neste momento.

Como é fato bastante conhecido, os filósofos dos séculos XVII e XVIII acreditavam que a primeira linguagem dos homens teria sido a de ação - os surdos a teriam conservado e aprimorado. A linguagem de ação, segundo os iluministas, seria uma forma de registro mais acurada da realidade, pois, como um espelho, refletiria o modo simultâneo como os sentidos percebiam o mundo exterior - seria deles, portanto, uma forma de representação desdobrada. A língua oral teria surgido como uma expansão lateral da linguagem de ação por conveniências impostas pelas necessárias adaptações ao ambiente - poder ser perceptível no escuro das cavernas, por exemplo (Cf. Foucault, 1992: 121-125).

Assim concebida, a linguagem de sinais teria um caráter universal, uma vez que todos os homens seriam dotados das mesmas condições de funcionamento dos sentidos e porque os objetos percebidos teriam sempre as mesmas características, independente do país. Quer dizer: se na linguagem de ação havia (supostamente) uma relação isomórfica entre o referente e as sensações, e, portanto, entre a coisa e o sinal correspondente, a langue des signes só poderia ser entendida como sendo, necessária e logicamente, comum a todos os povos.

No rastro deste raciocínio, Diderot (1993) em Carta Sobre os Surdosmudos Para Uso Dos Que Ouvem e Falam, publicada em 1775, considerou que as categorias gramaticais teriam aparecido, na origem das línguas orais, de modo a obedecer à lógica da percepção dos sentidos já submetidos aos 
signos: assim, primeiro teriam sido identificados os principais objetos dos sentidos (frutas, água, árvores etc) e as paixões (daí porque os nomes deveriam ter aparecido primeiro); depois os atributos das coisas (adjetivos); em seguida os modos de localizá-las no espaço (algumas formas adverbiais); e, em seguida, o reconhecimento de suas essências para além das aparências - os nomes metafísicos e os substantivos genéricos (Cf. Diderot, 1993: 18-19; $31)$.

Os verbos teriam aparecido depois e o único que, de fato significaria, como história (Foucault 1992: 111-112), seria o verbo "ser".

"Assim é que o verbo ser teria essencialmente por função reportar toda linguagem à representação que ele designa. $O$ ser em direção ao qual ele transborda os signos não é mais nem menos que o ser do pensamento. Comparando a linguagem a um quadro, um gramático do fim do século XVIII define os nomes como formas, os adjetivos como cores e o verbo como a própria tela onde elas aparecem".

Páginas depois, ainda seguindo a lógica iluminista no que se refere à linguagem, complementa:

"De sorte que todas as palavras, quaisquer que sejam são nomes adormecidos: os verbos juntaram nomes adjetivos ao verbo ser; as conjunções e as preposições são os nomes de gestos doravante imóveis; as declinações e as conjunções nada mais são que nomes absorvidos."(Foucault, 1992: 118, grifo meu. $)^{6}$

A partir das observações que fez da linguagem de um surdo que conheceu, Diderot (1993) afirmou que se poderia avaliar o grau de inversões (corrupções impostas pelo uso) de uma língua, e também, entre as dela com as demais ${ }^{7}$. A natureza de tais inversões tornaria uma língua mais própria a uma função do que a outra. Segundo ele, um gênio, independente da língua que usasse, poderia, sem dúvida, fazer excelentes e diferentes usos dela. Entretanto, defende que, por ter (supostamente) menos inversões, o francês era a língua

\footnotetext{
6 Foucault, nesse trecho, refere-se à idéia expressa por gramáticos como Sicard, citado inclusive por ele, de que muitos verbos derivaram de proposições nas quais sujeito e adjetivo eram ligados pelo verbo "ser". Assim, se originalmente se dizia "eu sou cantante", com o tempo os falantes da língua teriam inventado o verbo "cantar". Por sua vez, a palavra "cantante" ocultaria o nome do qual teria derivado: "canto". Haveria, pois, uma circularidade que desaguaria sempre no nome. Analisando as idéias dos gramáticos de Port Royal, Foucault explica o motivo: para eles toda e qualquer palavra da língua sempre ocultaria um nome, pois, ou teriam tomado o lugar dos objetos a que se referiam diretamente, ou teriam substituído o nome dos gestos com os quais os homens simulavam seus liames e sucessão.

As inversões era um tema que vinha sendo tratado por escritores franceses desde o século XVII, como admite o próprio Diderot em seu texto.
} 
apropriada para a ciência, enquanto o italiano melhor se aplicaria à situação de comércio ou de engodo.

"Persisto em meu sentimento: continuo acreditando que, em relação ao grego, ao latim, ao italiano, ao inglês, etc, o francês tem a vantagem do útil ao agradável" (Diderot, 1993: 64).

Esta era a concepção de linguagem que circulava em Paris nos dias de Desloges. Daí porque rebate às críticas de Deschamps da seguinte forma:

"Ele (Deschamps) comete um erro maior ao sugerir que, para o surdo, a linguagem de sinais é limitada a coisas físicas e necessidades corporais.

Isto é verdadeiro para aqueles que são privados da companhia de outras pessoas surdas, ou que são abandonados em asilos, ou isolados em alguns lugares das cidades. Isto prova, de modo inquestionável, que nós não aprendemos usualmente a língua de sinais com pessoas ouvintes. (...)

Nós (surdos) expressamos nós mesmos em todos os assuntos com muito mais ordem, precisão, rapidez do que se desfrutássemos das faculdades da fala e da audição."(Desloges, 1984: 36)

\section{Mais além continua:}

"A linguagem que usamos entre nós, sendo a imagem fiel do objeto expressado, é singularmente apropriada para fazer nossas idéias acuradas e, por extensão, nossa compreensão, por nos levar a formar o hábito de constante observação $e$ análise. Essa linguagem é viva; carrega sentimentos e desenvolve a imaginação. Nenhuma outra língua é mais apropriada para expressar grandes e fortes emoções." (Desloges, 1984: 37, grifos meus)

Portanto, mais duas teses são defendidas por Desloges nos trechos transcritos acima. A primeira delas é a de que a língua de sinais é uma forma de comunicação própria dos surdos que convivem entre si, e por isto, não é aprendida usualmente com ouvintes e nem em situações de isolamento dos surdos de seus pares. Além disto, é uma linguagem como qualquer outra (aliás, melhor que as demais já que isomórfica às sensações); longe de ser deficitária, seria a língua mais própria à expressão das emoções, a que mais poderia desenvolver a atenção e promover a concentração das idéias na mente, sem a necessidade da intermediação da reflexão. Reconhecendo-lhe um valor tão excepcional, conclui:

"Eu não entendo como uma linguagem como a linguagem de sinais - a mais rica em expressões, a mais enérgica, a mais incalculavelmente vantajosa em sua universal inteligibilidade - é ainda tão menosprezada e que somente o 
surdo a fale tal como é. Isto é, eu confesso, uma daquelas irracionalidades da mente humana que eu não posso explicar."(Desloges, 1984: 45-6, grifo meu)

Este enunciado é bastante provocativo, pois nos coloca, a nós ouvintes, que falamos e queremos fazer falar, em uma perspectiva radicalmente diferente, desta vez sob a perspectiva de um surdo que não entende o motivo pelo qual nós, ouvintes, ainda nos limitamos apenas em saber falar...

Em outra parte de seu texto, Desloges intuitivamente reconhece diferenças sintáticas entre os sinais e o francês:

"Não há tampouco (nos sinais) qualquer grande ambigüidade ou circunlocução na expressão do passado ou do futuro; freqüentemente nossa expressão em sinais será mesmo mais curta que na fala. Nós precisamos, por exemplo, somente de dois sinais para expressar o que vocês dizem em três palavras: la semaine prochaine, le mois qui vient, l'anné dernière. A frase le mois qui vient contem quatro palavras; entretanto, eu uso somente dois sinais para isto, um para o mês e um outro para o futuro, os sinais para o artigo le e para o pronome relativo que são supérfluos." (Desloges, 1984: 38, grifos do próprio autor)

O exemplo que oferece, em termos da falta de necessidade de artigos, é um assunto já muito discutido pelos lingüistas que estudam sinais. A questão do pronome relativo mereceria uma discussão à parte, pois há trabalhos que demonstram que eles estão presentes na língua, marcados, como diria depois Berthier, em 1840, pelo jogo da fisionomia. (Para uma discussão atual mais detalhada, sugiro a leitura de Quadros, 1999).

\section{As intuições "linguiísticas" de Ferdinand Berthier}

Se Desloges escreveu seu livro como réplica às investidas do cônego Deschamps contra a linguagem de sinais, Ferdinand Berthier, 61 anos depois, é convidado a escrever a biografia de L'Epée a pedido dos membros da Sociedade para as Ciências Morais, Letras e Artes de Seine-et-Oise, que lhe propuseram:

"Investigar qual era a condição social do surdo antes do abade de L'Epée, e que meios foram empregados para sua educação; usar essas duas investigações para conseguir uma exata apreciação da realização de Epée como fundador de uma nova instituição e como benfeitor da humanidade"(Berthier, 1984: 163).

A biografia, escrita sob a forma de ensaio, seria usada como argumento, por aquela Sociedade, para ser oferecido a Epée um prêmio póstumo: o reconhecimento público e "universal" de suas benfeitorias. 
Diante do texto que foi convidado a escrever, muito provavelmente, o jovem professor surdo tenha se deparado com uma situação extremamente constrangedora. Isto porque lhe cabia enaltecer os méritos de L'Epée, e ele, Berthier, condenava o modo como o abade havia se valido da língua de sinais francesa da época para criar o que o abade havia batizado como Sinais Metódicos. Nos dias de hoje, essa inventiva mais apropriadamente seria denominada de Francês Sinalizado.

Os sistemas orais sinalizados, como se sabe, não correspondem a línguas de sinais: têm a superestrutura da língua oral considerada, e emprestam o léxico da língua de sinais do país em questão de modo mais ou menos sistemático. A compreensão de Berthier sobre o sistema de L'Epée era bem próxima da visão que temos hoje sobre os sistemas orais sinalizados.

Para ele, os Sinais Metódicos eram corrupções gramaticais feitas deliberadamente por L'Epée a partir do latim e do francês. Mas porque dessas duas línguas? Porque sua inventiva pretendia não apenas (pretensamente) gramaticalizar os sinais, mas ao escolher os elementos mais "adequados" para esta gramaticalização, oferecer ao surdo um instrumento acurado para uma análise linear das idéias aglomeradas em sua mente . $^{8}$

Objetivo este que foi reconhecido textualmente por Condillac quando afirmou que L'Epée, com sua linguagem, podia conduzir os surdos:

"das idéias sensíveis às idéias abstratas, por análises simples e metódicas; $e$ se pode julgar o quanto sua linguagem de ação possui vantagens sobre os sons articulados de nossas governantas e tutores." (Condillac, 1947: 429-30, grifo meu).

Todavia, Berthier apostava na tese defendida por Bébian, um professor ouvinte que estudou, quando criança, na escola de L'Epée; depois de formado, foi contratado como professor de surdos por essa mesma instituição (mais ou menos por volta de 1810).

Para Bébian, a pessoa surda deveria ser educada em sua própria língua de sinais, e não através dos Sinais Metódicos. Os professores tinham que conhecê-la profundamente e, para isto, julgava necessário, além do preparo do mestre, a existência de um dicionário que descrevesse e explicasse os sinais. Além disto, seria importante uma outra inventiva: a elaboração de

\footnotetext{
8 Seria interessante ser lembrado aqui que, na época do abade L'Epée, o latim era a língua em que eram ministrados os sacramentos, as missas e as aulas de humanidades nas escolas em geral. Os "clássicos" literários", por exemplo, estavam em latim. Além do prestígio que conferia a quem a soubesse (fosse ouvinte ou surdo), como marca de erudição, acreditava-se, de modo circular, que o latim, como língua, permitiria ao pensamento ascender à própria erudição, isto é, atingir formas lógicas mais refinadas de organização.
} 
uma escrita própria para os sinais; e ele mesmo havia proposto uma, batizada por ele de mimography. (Cf. Bébian,1984: 139-142) ${ }^{10}$

A partir do que foi dito, pode-se entender a situação constrangedora de Berthier - ter que iluminar os feitos pedagógicos de L’Epée sem, todavia, como surdo, concordar com seu método de ensino - os Sinais Metódicos.

Não me aterei aqui ao modo hábil, do ponto de vista discursivo, como ele, elegantemente, procurou amenizar esta situação. A fim de me ater ao tema desta reflexão, recortarei de seu ensaio três aspectos: a importância que dá aos sinais no ensino de surdos; as críticas que faz aos enxertos gramaticais - ou em nossos termos - à hibridização da língua de sinais com a majoritária para atender a finalidades pedagógicas; e a definição que dá à língua de sinais.

Para Berthier, as idéias (o pensamento) deveriam ser, primeiramente, acessíveis ao surdo através dos sinais pois, sem eles, os exercícios articulatórios ou a datilologia não teriam o menor significado e acabariam por se transformar em um jogo mecânico de dedos ou lábios de valor comunicativo similar à fala de um papagaio. (Cf. Berthier, 1984: 178). Ou como exemplifica:

"O fato de Pereire ter enriquecido seu alfabeto manual com sinais indicando a pronúncia de palavras e variações de entoação não constitui um método, como ele quis persuadir Saboreaux; é um exercício, ou mais apropriadamente, um jogo de dedos que nada significa para alguém sem entendimento da linguagem falada." (Berthier, 1984: 173, grifo meu)

Como dito anteriormente, Berthier, seguindo a lógica de Bébian, também defendia que os sinais deveriam ser aqueles usados pelos surdos e não os que foram inventados por L'Epée. Entre outros motivos porque os Sinais Metódicos acabavam por gerar mais problemas do que por oferecer um meio seguro para o entendimento da palavra escrita em francês.

"Para traduzir palavras francesas, Epée procurou derivações do latim e francês; ele tentou distorcer a linguagem dos gestos, curvando-a aos hábitos e características da linguagem convencional sem perceber que uma língua ao se corromper para uma outra necessariamente se transforma em uma

\footnotetext{
${ }^{10}$ Atualmente, há vários pesquisadores que defendem tese similar, isto é, a de que os surdos deveriam ser alfabetizados primeiramente em Sign Writing, um sistema escrito dos sinais, e depois na escrita da língua majoritária. Esta idéia é endossada, entre outros, por Stumpf, 2002: 154. Capovilla, em 2001, publicou o primeiro dicionário da língua brasileira de sinais com a tradução dos significados e modos de uso, de cada item lexical sinalizado, para o português, inglês e Sign Writing.
} 
interpretação incorreta. A mímica ${ }^{10}$ não reconhece outro mestre senão a natureza e a razão; sua sintaxe é fixa, em oposição às mutáveis sintaxes das línguas faladas, particularmente a sintaxe do francês. A performance da mímica é bastante independente de regras gramaticais; ela voa tão rápido como o pensamento. Epée não tinha idéia da extensão do instrumento que criou. Para citar somente alguns poucos exemplos, entre milhares de outros possíveis, aqui está sua análise das palavras satisfaire, introduire, e intelligence. $O$ sinal satisfaire, ele disse, é inventado a partir de duas palavras latinas, facere e satis (fazer o suficiente) (...)

Portanto, a infortunada pessoa surda tinha que ser removida de sua própria comunidade e posta para aprender latim antes que pudesse aprender francês. Mas não era excêntrico, e improdutivo para a criança, se escolher o mais longo caminho para um objetivo tão urgente?"(Berthier, 1984: 181-182, grifos do autor)

No que se refere à gramática dos sinais, Berthier está inescapavelmente inscrito na ordem dos discursos considerados verdadeiros em sua época: os sinais, derivações mais puras da linguagem de ação, mais fielmente manteriam a sintaxe natural imposta pelo funcionamento das sensações. Daí porque ser fixa em suas regras de formação - uma vez que não teria outro "mestre senão a natureza e a razão” (p.182). Por outro lado, as sintaxes das línguas orais seriam mais instáveis, pois geograficamente limitadas a determinados países e, neles, às influências do uso corrente.

Berthier também considera, e com razão, que tais enxertos gramaticais mais atrapalhavam do que ajudavam a criança na compreensão da escrita do francês - alvo de L'Epée. Além do mais, geravam confusões na hora de se traduzir para a pessoa surda uma palavra sinalizada para o francês e viceversa. Dirigindo-se a seu leitor, Berthier questiona a que serviria uma tradução literal, palavra por palavra, de um texto. A nada, responde ele. E continua:

"Então, com a sintaxe ou com a expressão da mímica por que não nos atemos mais ao significado subjacente do que à forma literal na tradução de, digamos, algumas expressões figurativas em latim para uma outra língua como o francês? A necessidade e clareza da tradução requer a escolha de uma expressão equivalente em francês e não uma cópia escrava do original." (Berthier, 1984: 186)

\footnotetext{
10 As expressões língua de sinais, linguagem gestual e mímica eram utilizadas como sinônimas por autores franceses dos séculos XVIII e XIX. Como tive oportunidade de discutir em outra ocasião (Souza, 1998), atualmente tais expresões não são consideradas sinônimas. Em relação à diferença entre "gesto" e "sinal", pesquisas realizadas pelo grupo de Ursulla Bellugi com surdos afásicos vêm demonstrando que o cérebro humano distingue as representações espacias requeridas para funções não lingüísticas daquelas subjacentes às representações gramaticais dos sinais. Todavia há aspectos de entrelaçamento entre a língua (qualquer uma) com a gestualidade que ainda merecem uma maior compreensão; por exemplo, no que se refere às fronteiras que se costumam traçar entre o que seja elementos pragmáticos e discursivos daqueles considerados "sintáticos" no sentido estrito do termo.
} 
Daí a relevância, segundo ele, de o professor conhecer a gramática dos sinais, sua sintaxe particular e suas diferenças com as línguas faladas. $\mathrm{O}$ modo próprio de se usar as mãos para expressar a linguagem tornam os sinais tão singulares em relação às línguas orais como, por exemplo, segundo ele, distinguem-se, entre si, a poesia e a geometria (Cf. Berthier, 1984: 186).

Entretanto, lamenta a pouca compreensão que em sua época havia sobre o funcionamento gramatical dos sinais, o preconceito que este conhecimento gerava e a falta de clareza por parte das pessoas em geral sobre como poderia ser definida, afinal de contas, a língua de sinais.

Em relação a esse aspecto, Berthier narra o seguinte fato: em uma das apresentações públicas de L'Epée, Jacob Pereire teria perguntado ao abade se a linguagem dos sinais possuía tantos caracteres quanto a língua chinesa. Berthier retoma esta questão e responde:

"O espaço do tema aqui é limitado demais para tratar do número de caracteres na língua chinesa. Tudo que posso dizer sobre a linguagem de sinais é que, mesmo hoje, poucas pessoas falantes têm uma idéia precisa do que consiste essa linguagem e seu caráter especial. Muito mais simples do que normalmente se supõe, ela tem um número restrito de constituintes em um infinito número de combinações, e é avivada pelo jogo da fisionomia. Possui tudo que se requer para representar todas as idéias aglomeradas na mente e todos os afetos que excitam o coração." (Berthier, 1984: 175, grifo meu).

Como sabemos, mais de um século depois, Chomsky afirmará algo semelhante em relação às línguas em geral. Cada língua, segundo ele, deveria ser entendia como constituindo um sistema composto por um número limitado de elementos que se combinariam segundo "um conjunto finito de regras que permitem a criação de uma infinidade de frases" (Chomsky, livro não datado pela editora: 8 , grifo meu).

A intuição de Berthier vem ao encontro deste conhecido preceito chomskiano e, a partir de tal abordagem, com o que afirma também Quadros (2002) na conclusão de seu trabalho. Segundo ela, "as derivações visuaisespaciais seguem a mesma lógica das derivações orais-auditivas, ou seja, observam-se restrições na organização sintática que delimitam as possibilidades existentes na derivação das sentenças" (comunicação oral feita no XVII Encontro Nacional da Anpoll).

Em resumo, Berthier além de endossar as idéias defendidas por Desloges, ao menos as aqui apontadas ${ }^{11}$, se empenha em demonstrar que a língua de sinais tem os recursos sintáticos necessários para expressar qualquer

11 De modo distinto de Berthier, Desloges defendia o método de L'Epée por julgar que o abade havia conferido à língua de sinais o que nela, para ele, faltava: regras metódicas de uso. (Cf. Desloges, 1984: 34) 
pensamento ou fato e, portanto, deve ser utilizada tal como é no ensino das pessoas surdas e não confundida, ou embaralhada, com a sintaxe da língua oral.

\section{Considerações finais}

As idéias defendidas pelos dois autores surdos considerados neste trabalho coincidem com algumas defendidas em nosso tempo, quais sejam:

1- As pessoas surdas possuem uma compreensão própria e histórica sobre sua educação e a língua mais apropriada para subsidiá-la. Para muitos deles, a língua de sinais é a preferencial para a instrução, ao menos em uma escola pensada com e para surdos. (Desloges, 1779/1984; Berthier, 1840/1984; Perlin, 1998)

2- Sua aprendizagem prévia facilitaria a aquisição da língua escrita majoritária. (Freire, 1999)

3- A existência de dicionários da língua de sinais é um valioso instrumento tanto para o professor como para o aluno, pois facilita a aprendizagem (dos sinais), o acesso e a compreensão das palavras sinalizadas bem como sua versão à língua majoritária (Capovilla, 2001).

4- Continua sendo posta em discussão a possibilidade de o surdo ser alfabetizado na escrita dos sinais antes de o ser em português (Stumpf, 2002).

5- As línguas de sinais obedecem a regras gramaticais como qualquer outra língua (Quadros, 1999).

Entretanto, o fato que me parece mais estimulante é que a modalidade e natureza singulares dos sinais nos obrigam, de modo provocativo, a entendermos os princípios lingüísticos que regulam as línguas em geral necessariamente de um outro lugar - extremamente deslocado de onde aprendemos a estar. Condição que pode, quem sabe, nos levar à reavaliação de algumas "verdades" que inventamos e naturalizamos sobre este objeto, ainda tão fascinante e misterioso, que chamamos linguagem.

E-mail: reginasouza@ directnet.com.br Enviado em julho de 2002 Versão reformulada : junho de 2003

\section{REFERÊNCIAS BiBLIOGRáFICAS}

BERTHIER, Ferdinad. 1984. The Deaf Before and Since the Abbé de L'Epée. In: Harlan LANE \& Franklin PHILIP (eds.) The Deaf Experience - classics in language and education. Cambridge: Harvard University Press. (Texto 
original escrito em francês, Paris: Ledoyen, 1840).

Capovilla, Fernando César. 2001. Dicionário Enciclopédico Ilustrado

Trilingüe da Língua de Sinais Brasileira. 2 vols. São Paulo: Edusp, Fapesp, Feneis. Brasil Telecom..

Chomsky, Noam (sem data) Diálogos com Mitsou Ronat. São Paulo: Cultrix (original publicado pela editora Flammarion em 1977).

Condillac, Étienne Bonnot. 1947. Oeuvres Philosophiques. Paris: Presses

Universitaries de France.

Desloges, Pierre. 1984. A Deaf Person's Observations About an Elementary

Course of Education for The Deaf. In: Harlan LANE \& Franklin PHILIP (eds.) The Deaf Experience - classics in language and education. Cambridge: Harvard University Press. (Texto escrito em francês, Paris: Morin, 1779.)

Diderot, Denis. 1993. Carta sobre os surdos-mudos para uso dos que ouvem e falam. São Paulo: Nova Alexandria (publicado originalmente em francês em 1751).

Foucault, Michel. 1991. Vigiar e Punir. 9a edição. Petrópolis: Vozes. .1992. As Palavras e as Coisas. $6^{\text {a }}$ edição brasileira, São Paulo: Martins Fontes.

. 1998. Microfísica do Poder. 13ª edição. Rio de Janeiro: Graal.

FreIRE, Alice Maria da Fonseca. 1999. Aquisição do Português como Segunda Língua: uma proposta de currículo para o Instituto Nacional de Educação de Surdos. In:, Carlos Skliar (org.) Atualidade da Educação Bilíngüe para Surdo. vol. 2. Porto Alegre: Mediação.

Kyle, James. 1994. (ed.) Growing up in Sign and Word. Grã Bretanha: Antony Rowe Ltd.

Lane, Harlan \& Franklin PHILIP. 1984. The Deaf Experience - classics in language and education. Cambridge: Harvard University Press.

Narodowski, Mariano. 2001. Infância e Poder: conformação da pedagogia moderna. Bragança Paulista: Editora da Universidade São Francisco.

Padden, Carol \& Tom Humphries. 1988. Deaf in América - Voices from a Culture. Cambridge: Harvard University Press.

Perlin, Gladis Teresinha Taschetto. 1998. Histórias de Vida Surda.

Dissertação de Mestrado: Programa de Pós-graduação em Educação, Faculdade de Educação. Porto Alegre: Universidade Federal do Rio Grande do Sul.

Quadros, Ronice Muller. 1999. Phrase Structure of Brazilian Sign Language. Tese de doutorado, Curso de Pós-graduação em Letras da Pontifícia Universidade Católica do Rio Grande do Sul.

.2002. Gramática da Língua de Sinais Brasileira. Trabalho apresentado na Mesa Redonda: Investigações Sobre a Língua de Sinais Brasileira. 
Boletim Informativo, 31 do XVI Encontro Nacional da ANPOLL: 346. Roсн-Ambroise, Bebian. 1984. Essay on The Deaf Natural Language, or Introduction to a Natural Classification of Ideas With Their Proper Signs. In: Harlan LANE \& Franklin PHILIP (eds.) The Deaf Experience - classics in language and education. Cambridge: Harvard University Press (original em francês, Paris: Dentu, 1817).

Skliar, Carlos. 1999. Atualidade da Educação Bilíngüe para Surdos. Porto Alegre: Mediação.

SouzA, Regina Maria. 1998. Que palavra que te falta? Lingüística e educação: considerações epistemológicas a partir da surdez. São Paulo: Martins Fontes.

SouZA, Regina Maria \& CARDOso, Silvia Helena Barbi. 2001. Inclusão escolar e linguagem: revisitando os PCNs. Pró-posições, 12, n. 2-3: 35-36/ 3246.

StumpF, Marianne Rossi. 2002. Como o Pesquisador Surdo Constrói a Teoria na Pós-graduação. Boletim Informativo, 31 do XVI Encontro Nacional da ANPOLL: 154. 